\title{
Juniperus communis Extract Effect on Bronze Corrosion in Natural 0.5 M Chloride Medium
}

\author{
Refka Ben Channouf ${ }^{1}$, Nebil Souissi' ${ }^{2}$, Nizar Bellakhal ${ }^{1}$ \\ ${ }^{1}$ Carthage University, Institut National des Sciences Appliquées et Technologie, Unité de Recherche "Catalyse, \\ Electrochimie, Nanomatériaux et leurs Applications et Didactique" Centre Urbain Nord de Tunis, Tunis, Tunisia \\ ${ }^{2}$ Tunis El Manar University, Institut Préparatoire aux Etudes d'Ingénieurs El Manar, Campus Universitaire EI \\ Manar, Tunis, Tunisia \\ Email: refka.benchannouf@gmail.com
}

Received 7 September 2015; accepted 13 November 2015; published 20 November 2015

Copyright (C) 2015 by authors and Scientific Research Publishing Inc.

This work is licensed under the Creative Commons Attribution International License (CC BY).

http://creativecommons.org/licenses/by/4.0/

(c) $\underset{\mathrm{EY}}{(\mathbf{0})}$ Open Access

\begin{abstract}
The effect of Juniperus communis (JC) extract on the inhibition of bronze corrosion in aqueous chloride solution was studied by electrochemical polarization methods. The variation of two experimental factors such as the chloride concentration and the temperature allows us to deduce the kinetics parameters of this process $\left(E a=65.7 \mathrm{~kJ} \cdot \mathrm{mol}^{-1}\right)$. Thermodynamic calculations indicated that JC adsorption on bronze surface obeyed Arrhenius adsorption isotherm and was characterized by an endothermic process $\left(\Delta H^{*}=54.7 \mathrm{~kJ} \cdot \mathrm{mol}^{-1}\right)$.
\end{abstract}

\section{Keywords}

Synthetic Bronze, Corrosion Inhibition, Green Inhibitor, Juniperus communis

\section{Introduction}

Corrosion is the deterioration of metal by chemical attack or reaction with its environment. It is a constant and continuous problem, often difficult to eliminate completely. Prevention would be more practical and achievable than complete elimination [1]. The knowledge of the causes of corrosion is essential to develop a control technology and to improve the means of protection.

The term bronze recovers in the old objects in a large number of nuances of alloys. In most cases, these are materials composed of copper and tin, the tin content is between $4 \%$ and $15 \%$ by mass. 
The protection of pure copper [2]-[10] or its alloys [11] against corrosion was the concern of researches for a long time. This work is interested in the study of corrosion inhibition of copper alloys such as bronze defined previously. The use of inhibitors is one of the most practical methods for bronze corrosion protection. A number of organic compounds have been reported as effective corrosion inhibitors.

Dermaj et al. [12] showed that 3-phenyl-1,2,4 triazole-5-thione (PTS) was a corrosion inhibitor of a binary bronze (Cu-Sn 8) when subjected to a corrosive solution of $3 \% \mathrm{NaCl}$. It had proven to be a mixed inhibitor which was acted by adsorption to the surface of the material. The inhibition efficiency was $99.8 \%$ at a concentration of $0.1 \mathrm{mM}$ PTS.

Varvara et al. [13] studied the efficiency inhibition of some organic compounds such as the 2-mercapto-5amino-1,3,4-thiadiazole (MAT) for the bronze protection in a solution of $0.2 \mathrm{~g} \cdot \mathrm{L}^{-1} \mathrm{Na}_{2} \mathrm{SO}_{4}$ and $0.2 \mathrm{~g} \cdot \mathrm{L}^{-1} \mathrm{NaHCO}_{3}$. The inhibition efficiency was greater than $90 \%$.

Rahmouni and Takenouti [14] were interested in the protection of archaeological Moroccan coins patinated bronzes by derivatives of triazoles: benzotriazole, triazole and bi-amino-triazole.

Hu et al. [15] has combined benzotriazole (BTA) with the sodium molybdate for use as a corrosion inhibitor of bronze in $\mathrm{NaCl}$ solution $0.5 \mathrm{~mol} \cdot \mathrm{L}^{-1}$.

As for Stupnisek Lisac et al. [16], they confirmed that the 1-phenyl-4-methyl-imidazole and 1-(p-tolyl)-4-methylimidazole were bronze corrosion inhibitors. They protected the layer of the patina of bronze.

Muresan et al. [17] reported that the 4-methyl-1-(p-tolyl)-imidiazole (TMI), 1-phenyl-4-methyl imidazole (PMI), the 2-mercapto 5-R-acetylamino-1,3, 4-thiadiazole (MAcT) and 2-mercapto 5-R-amino-1,3,4-thiadiazole (MAT) were corrosion inhibitors of bronze (Cu-Sn 6) in a solution of $0.2 \mathrm{~g} \cdot \mathrm{L}^{-1} \mathrm{NaHCO}_{3}$ and $0.2 \mathrm{~g} \cdot \mathrm{L}^{-1} \mathrm{Na}_{2} \mathrm{SO}_{4}$.

In another work, Varvara et al. [18] has demonstrated that DL-alanine and DL cysteine are bronze corrosion inhibitors in the presence of an aqueous solution of $0.2 \mathrm{~g} \cdot \mathrm{L}^{-1} \mathrm{Na}_{2} \mathrm{SO}_{4}+0.2 \mathrm{~g} \cdot \mathrm{L}^{-1} \mathrm{NaHCO}_{3}$ to $\mathrm{pH}=5$. Those are cathodic inhibitors which are absorbed on the surface of bronze by forming a protective organic layer. The efficiency of inhibition is $90 \%$ at a concentration which equals to $0.1 \mathrm{mM}$ cysteine.

However, most of these organic compounds reported in the literature as effective corrosion inhibitors are toxic to humans and environments. Hence, several research teams tested plant extracts as ecofriendly inhibitors [1]. However, the effects of such mixtures on tin bronze corrosion were poorly studied [19].

This work is a trial to test a plant extract of Juniperus communis as corrosion inhibitor of synthetic bronze (Cu10Sn).

Juniperus communis is in the genus Juniperus, in the family Cupressaceae. It has the largest range of any woody plant, throughout the cool temperate Northern Hemisphere from the Arctic south in mountains to around $30^{\circ} \mathrm{N}$ latitude in North America, Europe and Asia.

The aim of the present work is to study the effects of a Juniperus communis extract (JC) on the interfacial behaviour of a modern bronze (Cu10Sn). Polarization curves are used in order to understand the alloy corrosion behaviour in aqueous $0.5 \mathrm{M}$ chloride medium without and with the extract addition.

\section{Experimental}

\subsection{Preparation of the Green Inhibitors from JC}

The maceration is the method of extraction; it consists in letting soak $100 \mathrm{~g}$ of the Juniperus Communis (JC) (Figure 1) in $100 \mathrm{~mL}$ of methanol during 24 hours. The extract is then filtered and used directly without additional treatment. Sodium chloride $0.5 \mathrm{~mol} \cdot \mathrm{L}^{-1}$ was used as corrosive environment.

\subsection{Electrochemical Study}

The working electrode was prepared from a synthetic bronze (Cu10Sn) [20]. Before use, it has been coated with a chemically inert resin and polished using a polisher with abrasive paper up to 4000 under a stream of water to avoid any change in crystal structure. It is transported in alcohol and rinsed thoroughly with distilled water before being immersed in the electrolyte. A classical three-electrode cell was used for the electrochemical characterizations with a saturated calomel electrode as reference and platinum wire as counter electrode. Experiments were conducted on a Voltalab 80. Voltmaster 4 software was used for instrumentation control and data treatment. All the results are given with respect to the saturated calomel electrode. 


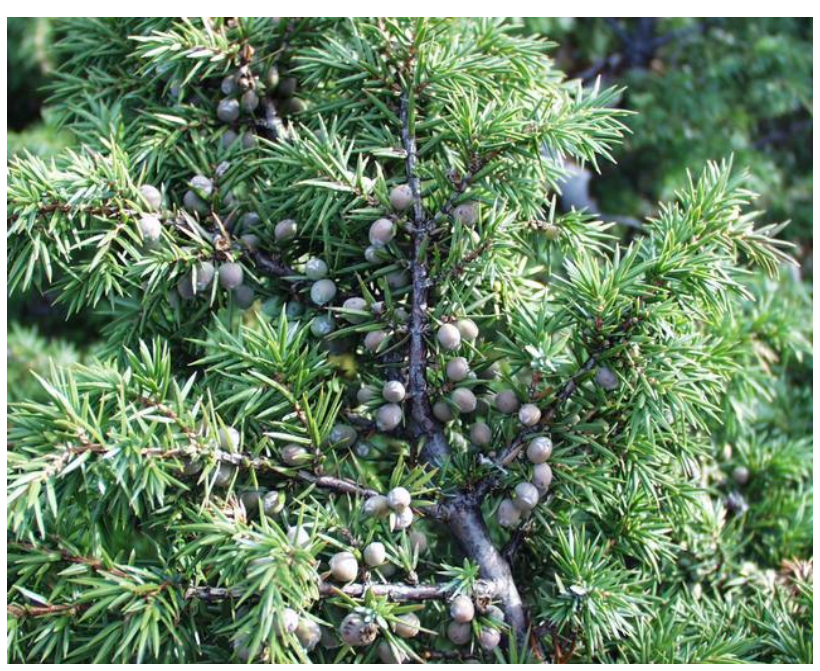

Figure 1. Picture of the juniperus communis.

\section{Results and Discussions}

\subsection{Electrochemical Behavior of Synthetic Bronze in the Absence and Presence of the Extract of the JC in $\mathrm{NaCl} 0.5 \mathrm{~mol} \cdot \mathrm{L}^{-1}$}

Figure 2 gathers the polarization curves of synthetic bronze immersed for one hour at $303 \mathrm{~K}$ in chloride solution $0.5 \mathrm{~mol} \cdot \mathrm{L}^{-1}$ with and without addition of the JC extract. The curves are plotted with a potential scan rate of 10 $\mathrm{mV} \cdot \mathrm{s}^{-1}$.

The extrapolation of Tafel lines at the corrosion potential gave access to electrochemical parameters: corrosion potential (Ecorr), anodic Tafel slope $(\beta a)$, cathodic Tafel slope $(\beta c)$, corrosion current (Icorr), polarization resistance (Rp) and percentage of inhibition efficiency (\%IE). These parameters are reported in Table 1.

The comparison of the electrochemical behavior of (Cu10Sn) in chloride medium, with and without addition of the JC extract show an increase in the cathodic slope value and a decrease in the anodic one.

However, the effect of the inhibitor on the anodic Tafel slope is negligible indicating that the inhibitor exerts its action via simple blocking, and that the adsorption of the inhibitor does not change the mechanism for the anodic reaction, so we can consider that JC extract is a cathodic inhibitor because it affects the cathodic reaction.

The corrosion current shows a drop of about $15 \mu \mathrm{A} \cdot \mathrm{cm}^{-2}$ after the introduction of the JC extract.

In contrast, the polarization resistance presents an opposite behavior. In fact, it was equal to $5.3 \mathrm{k} \Omega \cdot \mathrm{cm}^{-2}$ and $13.5 \mathrm{~K} \cdot \mathrm{k} \Omega \cdot \mathrm{cm}^{-2}$, respectively, for the chloride solution without and with the addition of JC extract.

When using the following equation (Equation (1)) a percentage of inhibition efficiency of about $63 \%$ was calculated.

$$
\% \mathrm{IE}=\left[\frac{\operatorname{Icorr}(\mathrm{NaCl})-\operatorname{Icorr}(\mathrm{NaCl}+\mathrm{JC})}{\operatorname{Icorr}(\mathrm{NaCl})}\right] * 100
$$

where Icorr $(\mathrm{NaCl})$ and Icorr $(\mathrm{NaCl}+\mathrm{JC})$ are corrosion current densities in the absence and presence of extract, respectively.

\subsection{Temperature Effect on the Voltammetric Behaviour of the Synthetic Bronze in Absence and Presence of JC Extract}

To determine the influence of temperature on the interfacial behaviour of the material, without and with addition of the JC extract, IE curves were drawn after an hour of immersion in a chloride electrolyte with scan rate 10 $\mathrm{mV} \cdot \mathrm{s}^{-1}$. The results are reported in Figure 3 .

It was observed that when the temperature increased, the corrosion current increased.

From these curves, characteristic electrochemical parameters Ecorr, $\beta \mathrm{a}, \beta \mathrm{c}$ and Icorr were determined and listed in Table 2. 


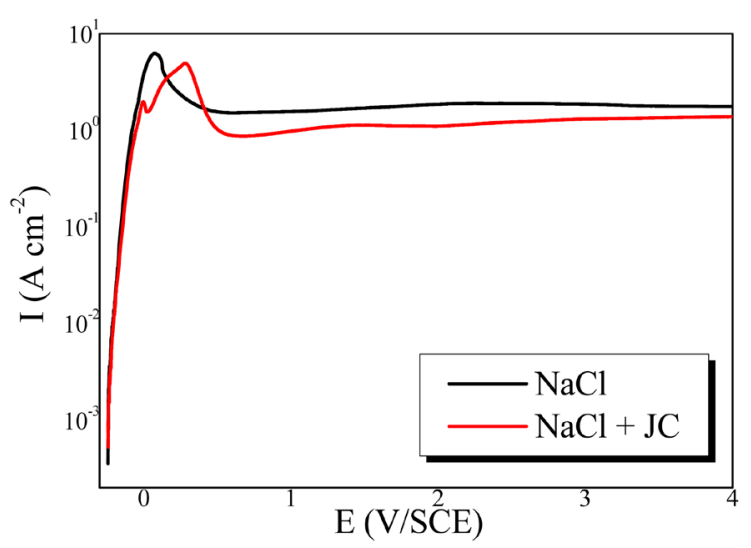

(a)

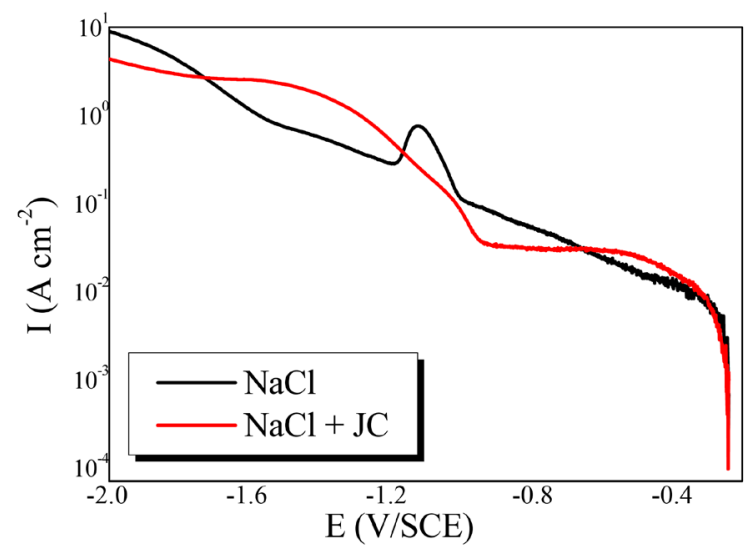

(b)

Figure 2. Bronze polarization curves ((a) anodic; (b) cathodic) immersed at $303 \mathrm{~K}$ for one hour in a solution of Sodium chloride $0.5 \mathrm{~mol} \cdot \mathrm{L}^{-1}$ with scan rate $10 \mathrm{mV} \cdot \mathrm{s}^{-1}$ without and with addition of the $\mathrm{JC}$ extract.

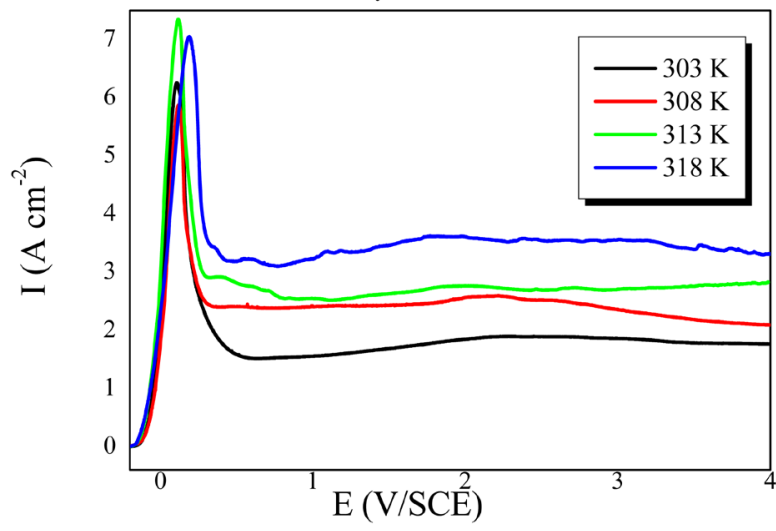

(a)

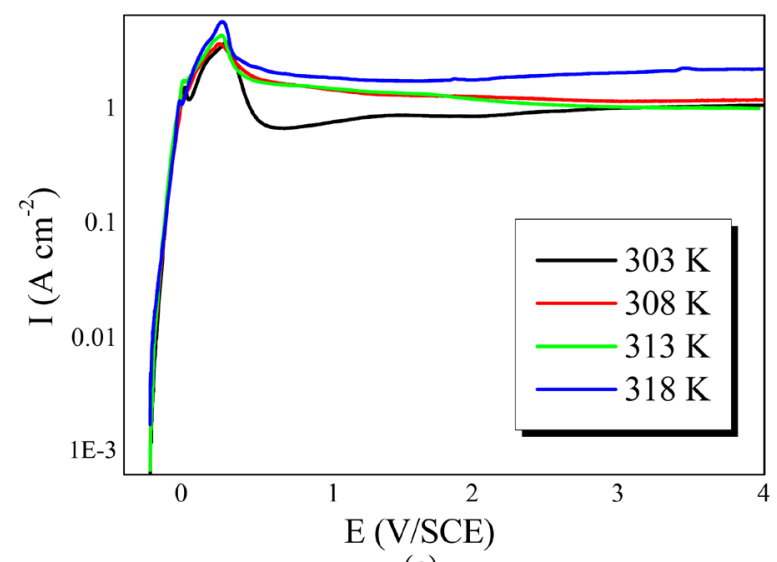

(c)

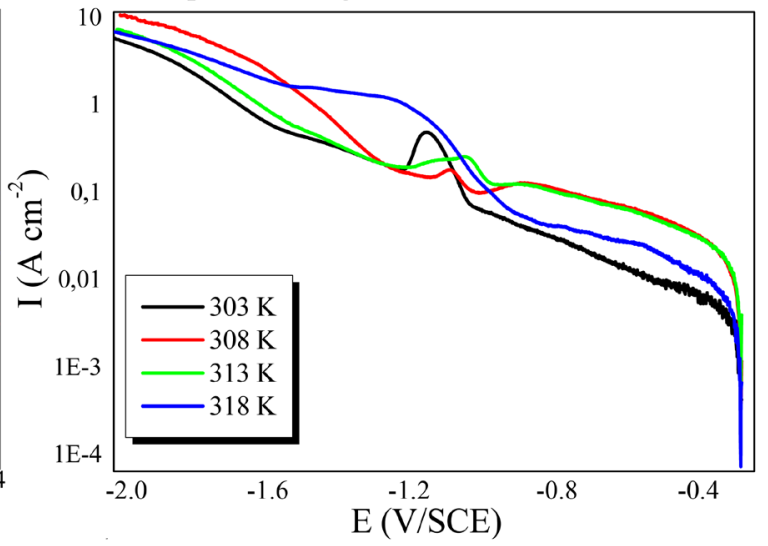

(b)

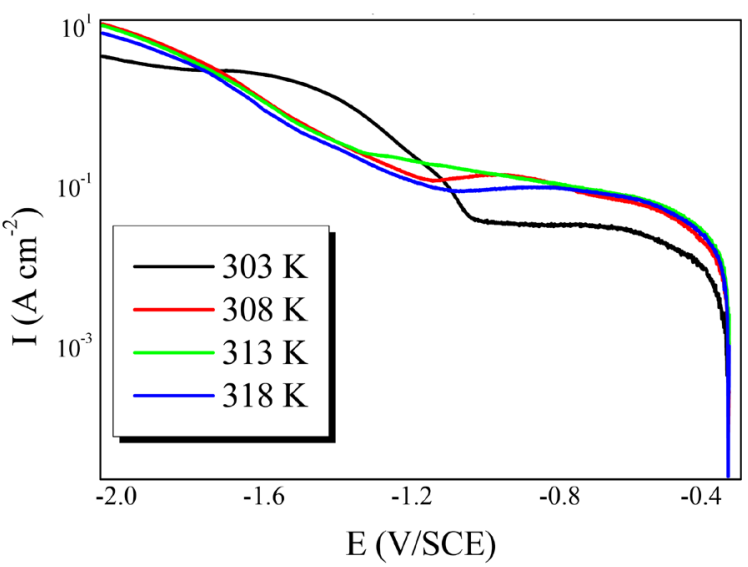

(d)

Figure 3. Bronze polarization curves ((a) anodic curve without JC; (b) cathodic curve without JC; (c) anodic curve with JC; (d) cathodic curve with JC) immersed for one hour in a solution of sodium chloride $0.5 \mathrm{~mol} \cdot \mathrm{L}^{-1}$ with scan rate $10 \mathrm{mV} \cdot \mathrm{s}^{-1} \mathrm{de}-$ pending on the temperature.

\section{Kinetic Parameters for Inhibitor}

The dependence of the corrosion rate on temperature is given by the Arrhenius equation [21] [22] (Equation (2)) 
Table 1. Electrochemical parameters of synthetic bronze immersed in a solution of $\mathrm{NaCl}$ with and without the JC extract.

\begin{tabular}{|c|c|c|c|c|c|c|}
\hline Solutions & $\begin{array}{c}\text { Ecorr } \\
\text { (V/SCE) }\end{array}$ & $\beta \mathrm{a}\left(\mathrm{V}^{-1}\right)$ & $\beta c\left(\mathrm{~V}^{-1}\right)$ & $\begin{array}{c}\text { Icorr } \\
\left(\mu \mathrm{A} \cdot \mathrm{cm}^{-2}\right)\end{array}$ & $\begin{array}{c}\mathrm{Rp} \\
\left(\mathrm{k} \Omega \cdot \mathrm{cm}^{-2}\right)\end{array}$ & $\%$ IE \\
\hline $\mathrm{NaCl}\left(0.5 \mathrm{~mol} \cdot \mathrm{L}^{-1}\right)$ & -0.236 & 0.075 & -0.596 & 7.0 & 5.3 & -- \\
\hline $\mathrm{NaCl}\left(0.5 \mathrm{~mol} \cdot \mathrm{L}^{-1}+\mathrm{JC}\right)$ & -0.242 & 0.063 & -0.130 & 2.6 & 13.5 & 62.8 \\
\hline
\end{tabular}

Table 2. Evolution of the electrochemical parameters as a function of temperature for (Cu10Sn) immersed for one hour in the $\mathrm{NaCl}$ solution with and without addition of extract.

\begin{tabular}{ccccccccc}
\hline & \multicolumn{3}{c}{$\mathrm{NaCl}\left(0.5 \mathrm{~mol} \cdot \mathrm{L}^{-1}\right)$} & \multicolumn{5}{c}{$\mathrm{NaCl}\left(0.5 \mathrm{~mol} \cdot \mathrm{L}^{-1}\right)+\mathrm{JC}(10 \%)$} \\
$\mathrm{T}(\mathrm{K})$ & $\begin{array}{c}\text { Ecorr } \\
(\mathrm{V} / \mathrm{SCE})\end{array}$ & $\begin{array}{c}\beta \mathrm{a} \\
\left(\mathrm{V}^{-1}\right)\end{array}$ & $\begin{array}{c}\beta \mathrm{c} \\
\left(\mathrm{V}^{-1}\right)\end{array}$ & $\begin{array}{c}\text { Icorr } \\
\left(\mu \mathrm{A} \cdot \mathrm{cm}^{-2}\right)\end{array}$ & $\begin{array}{c}\text { Ecorr } \\
(\mathrm{V} / \mathrm{SCE})\end{array}$ & $\begin{array}{c}\beta \mathrm{a} \\
\left(\mathrm{V}^{-1}\right)\end{array}$ & $\begin{array}{c}\beta \mathrm{c} \\
\left(\mathrm{V}^{-1}\right)\end{array}$ & $\begin{array}{c}\text { Icorr } \\
\left(\mu \mathrm{A} \cdot \mathrm{cm}^{-2}\right)\end{array}$ \\
\hline 303 & -0.236 & 0.075 & -0.596 & 7.0 & -0.242 & 0.063 & -0.130 & 2.6 \\
308 & -0.260 & 0.091 & -0.148 & 12.7 & -0.221 & 0.068 & -0.097 & 4.5 \\
313 & -0.197 & 0.076 & -0.257 & 17.8 & -0.183 & 0.073 & -0.088 & 5.8 \\
318 & -0.209 & 0.075 & -0.549 & 19.9 & -0.220 & 0.094 & -0.197 & 9.5 \\
\hline
\end{tabular}

$$
\text { Icorr }=A \exp \left(\frac{-E a}{R T}\right)
$$

where $E a$ represents the apparent activation energy, $A$ is the pre-exponential factor, Icorr is the corrosion rate, $R$ is molar gas constant $\left(R=8.314 \mathrm{~J} \cdot \mathrm{mol}^{-1} \cdot \mathrm{K}^{-1}\right)$ and $T$ is absolute temperature.

Figure 4 shows the Arrhenius plots of Ln (Icorr) vs. $10^{3} / \mathrm{T}$ in the absence and presence of JC extract at different temperatures.

The values of Ea listed in Table 3 are obtained from the slopes of the Arrhenius plots. The linear regression coefficients of all plots are over 0.9 indicates the validation of the employed kinetic mode.

The increase in the value of Ea in the presence of inhibitor indicates a strong adsorption of the inhibitor molecules at the metal surface.

It has been reported that there are several cases regarding the effect of an inhibitor on the activation energy and inhibition efficiency; 1st case \%IE decrease with increasing temperature and Ea in the presence of the inhibitor is larger compared with the blank, 2nd case \%IE increase with temperature and Ea in the presence of the inhibitor is lower compared with the blank and the third case \%IE is independent of temperature and $E a$ values in the absence and presence of inhibitor are the same. In the present case both \%IE and Ea increased with the temperature increase. The increase in the activation energy might classify the adsorption of JC as a physical one [22]-[24].

\subsection{Concentration Effect of JC Extrat on the Voltammetric Behaviour of the Synthetic Bronze}

A study of the concentration of the JC extract was also conducted. I-E curves of the (Cu10Sn), immersed for one hour at $303 \mathrm{~K}$ in $0.5 \mathrm{~mol} \cdot \mathrm{L}^{-1} \mathrm{NaCl}$ with different concentrations of the extract are given in Figure 5.

We reported in Table 4 the electrochemical parameters at different temperatures to volume ratios in JC.

Table 4 shows the dependence of the inhibition efficiency on the concentration; the dependence is of sigmoid shape \%IE increases with the concentration until it reaches a plateau at inhibition efficiency $75 \%$ about indicating the significant inhibition efficiency of the present inhibitor under the present conditions.

The results obtained allowed the verification of the Arrhenius law for different levels of extract (Figure 6).

The activation thermodynamic parameters of bronze namely, the enthalpy of activation $\left(\Delta H^{*}\right)$ and entropy of activation $\left(\Delta S^{*}\right)$ are obtained from the transition state Equation (3):

$$
\text { Icorr }=\frac{R T}{N h} \exp \left(\frac{\Delta S^{*}}{R}\right) \exp \left(\frac{-\Delta H^{*}}{R T}\right)
$$

where $N$ and $h$ are Avogadro's number and Plank's constant respectively. 


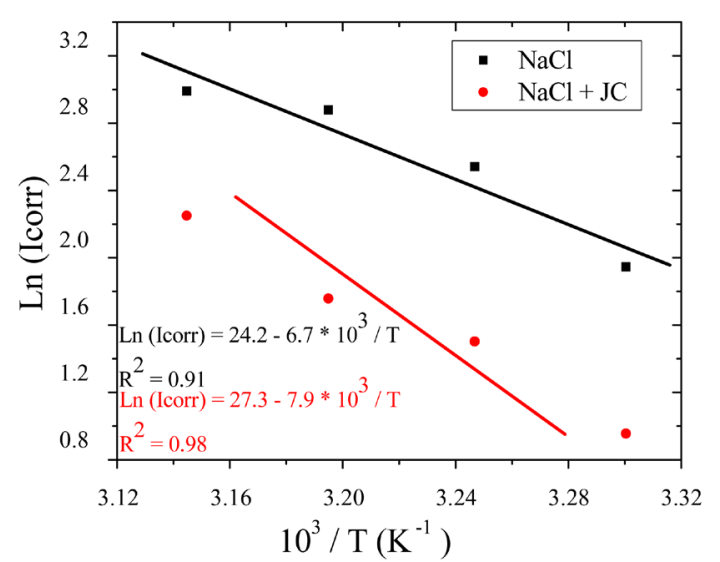

Figure 4. Arrhenius diagram for Cu10Sn immersed for one hour in the $\mathrm{NaCl}$ solution $0.5 \mathrm{~mol} \cdot \mathrm{L}^{-1}$ (scan rate $10 \mathrm{mV} \cdot \mathrm{s}^{-1}$ ) without and with addition of the JC extract.

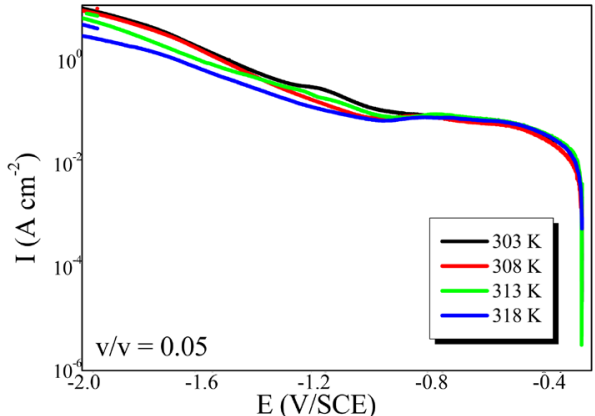

(a)

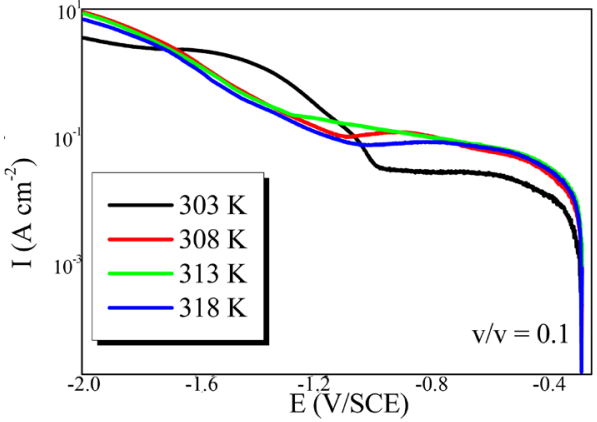

(c)

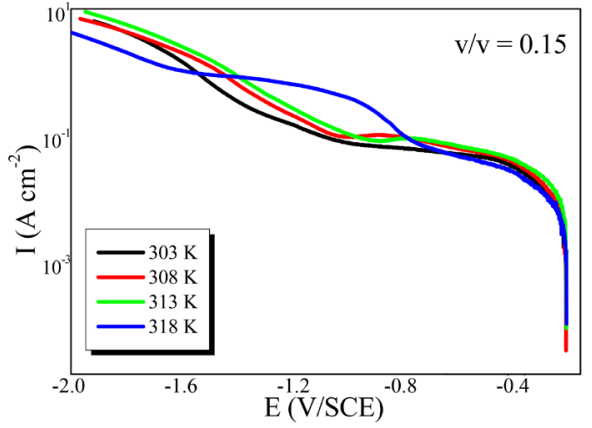

(e)

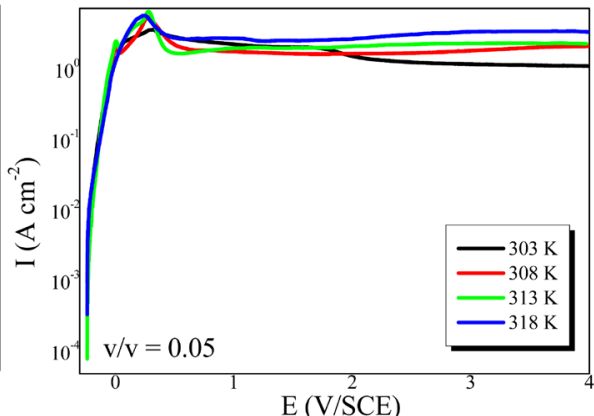

(b)

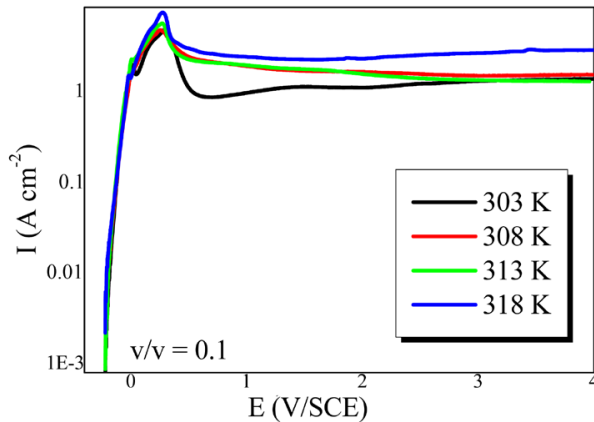

(d)

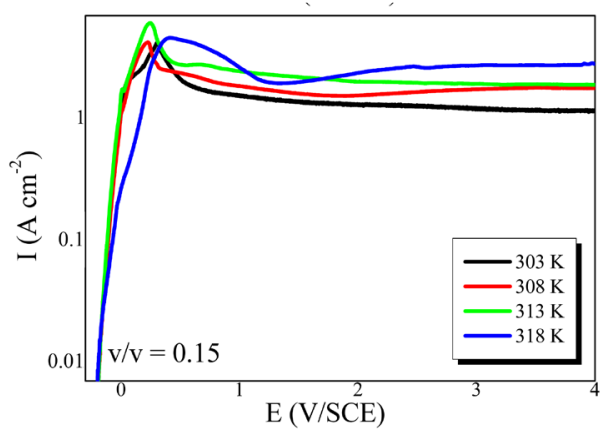

(f)

Figure 5. Polarization curves of synthetic bronze immersed for one hour in a solution of sodium chloride $0.5 \mathrm{~mol} \cdot \mathrm{L}^{-1}$ (scan rate $10 \mathrm{mV} \cdot \mathrm{s}^{-1}$ ) (a) (c) (e): cathodic curves) (b) (d) (f): anodic curves) with addition of the JC extract to different concentrations and different temperatures. 


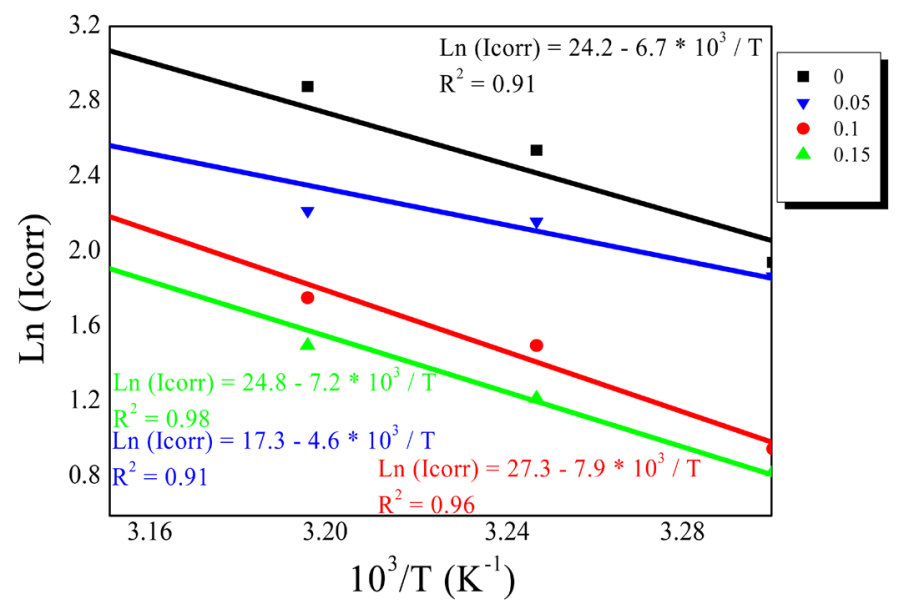

Figure 6. Arrhenius law for different concentrations of JC extract.

Table 3. Values of the activation energy of the process with and without addition of the extract. The $\mathrm{NaCl}$ concentration was $0.5 \mathrm{~mol} \cdot \mathrm{L}^{-1}$.

\begin{tabular}{ccc}
\hline Medium & $\mathrm{NaCl}\left(0.5 \mathrm{~mol} \cdot \mathrm{L}^{-1}\right)$ & $\mathrm{NaCl}\left(0.5 \mathrm{~mol} \cdot \mathrm{L}^{-1}\right)+\mathrm{JC}(10 \%)$ \\
\hline$E a\left(\mathrm{~kJ} \cdot \mathrm{mol}^{-1}\right)$ & 55.7 & 65.7 \\
\hline
\end{tabular}

Table 4. Electrochemical parameters of synthetic bronze immersed for one hour in a solution of sodium chloride $0.5 \mathrm{~mol} \cdot \mathrm{L}^{-1}$ (scan rate $10 \mathrm{mV} \cdot \mathrm{s}^{-1}$ ) with addition of the JC extract to different concentrations and different temperatures.

\begin{tabular}{|c|c|c|c|c|c|c|}
\hline & $\mathrm{T}(\mathrm{K})$ & Ecorr (V/SCE) & $\beta \mathrm{a}\left(\mathrm{V}^{-1}\right)$ & $\beta c\left(\mathrm{~V}^{-1}\right)$ & Icorr $\left(\mu \mathrm{A} \cdot \mathrm{cm}^{-2}\right)$ & $\% \mathrm{IE}$ \\
\hline \multirow{4}{*}{0.05} & 303 & -0.227 & 0.078 & -0.072 & 6.5 & 7.1 \\
\hline & 308 & -0.231 & 0.084 & -0.160 & 8.7 & 31.4 \\
\hline & 313 & -0.211 & 0.087 & -0.129 & 9.2 & 48.3 \\
\hline & 318 & -0.236 & 0.117 & -0.305 & 14.4 & 27.6 \\
\hline \multirow{4}{*}{0.1} & 303 & -0.242 & 0.063 & -0.130 & 2.6 & 62.8 \\
\hline & 308 & -0.221 & 0.068 & -0.097 & 4.5 & 64.5 \\
\hline & 313 & -0.183 & 0.073 & -0.088 & 5.8 & 67.4 \\
\hline & 318 & -0.220 & 0.094 & -0.197 & 9.5 & 52.2 \\
\hline \multirow{4}{*}{0.15} & 303 & -0.227 & 0.036 & -0.068 & 2.3 & 67.1 \\
\hline & 308 & -0.215 & 0.060 & -0.075 & 3.4 & 73.2 \\
\hline & 313 & -0.204 & 0.062 & -0.064 & 4.5 & 74.7 \\
\hline & 318 & -0.208 & 0.096 & -0.301 & 7.4 & 62.8 \\
\hline
\end{tabular}

Table 5. Values of the quantities $\Delta H^{\#}$ and $\Delta S^{\#}$ depending on the electrolyte content of the extract.

\begin{tabular}{|c|c|c|}
\hline Extract concentration (v/v) & $\Delta H^{*}\left(\mathrm{~kJ} \cdot \mathrm{mol}^{-1}\right)$ & $\Delta S^{*}\left(\mathrm{~J} \cdot \mathrm{mol}^{-1} \cdot \mathrm{K}^{-1}\right)$ \\
\hline 0.00 & 53.3 & -945.5 \\
\hline 0.05 & 36.6 & -1002.9 \\
\hline 0.10 & 54.7 & -948.6 \\
\hline 0.15 & 57.7 & -941.4 \\
\hline
\end{tabular}

Figure 7 shows the relation between Ln (Icorr/T) vs. $1 / T . \Delta H^{*}$ and $\Delta S^{*}$ were obtained from the slope and intercept, respectively and given in Table 5. 


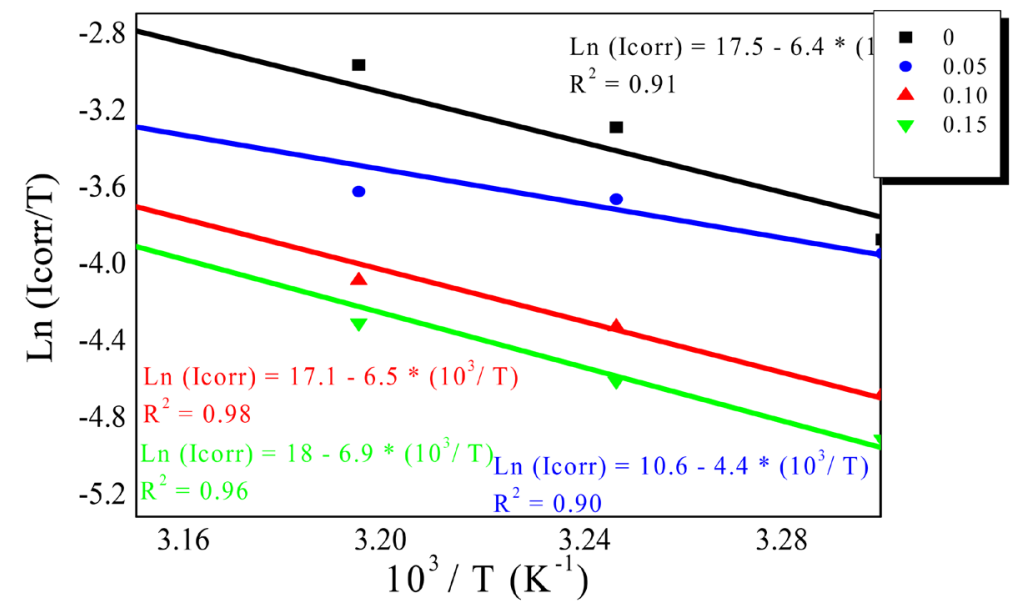

Figure 7. Transition state plots for the corrosion of $\mathrm{Cu} 10 \mathrm{Sn}$ in $0.5 \mathrm{~mol} \cdot \mathrm{L}^{-1} \mathrm{NaCl}$ (scan rate $10 \mathrm{mV} \cdot \mathrm{s}^{-1}$ ) in the absence and presence of JC extract.

The positive sign of $\Delta H^{*}$ reflects the endothermic nature of the dissolution process. The large and negative sign of $\Delta S^{*}$ in the absence and presence of the inhibitor implying that the activated complex in the rate-determining step represents association rather than dissociation, meaning that a decrease in disorder takes place, going from reaction to the activated complex [25].

\section{Conclusions}

Our study reports the effect of Juniperus communis (JC) extract on the protection of synthetic bronze (Cu10Sn) corrosion in a natural 0.5 chloride medium by electrochemical stationary investigations. Its corrosion inhibition efficiency tends towards $62.8 \%$.

However, from the aforementioned results it is apparent that with a temperature of $313 \mathrm{~K}$ and an extract concentration of $15 \%$, we obtain a maximum value of inhibition which almost equals to $75 \%$.

JC extract is endowed with a capacity to inhibit bronze corrosion in aqueous chloride solution by the physisorption of its molecules on the surface of the material.

The variation of the temperature and concentration of the extract allows the verification of the Arrhenius law for different levels of extract.

The thermodynamic properties of the adsorption process show that JC extract is adsorbed on the metal surface at an endothermic process ( $\Delta H^{*}$ is positive) and tends to decrease the molecular disorder in the interface ( $\Delta S^{*}$ value is negative).

\section{References}

[1] Amitha Rani, B.E. and Basu, B.B.J. (2012) Green Inhibitors for Corrosion Protection of Metals and Alloys: An Overview. International Journal of Corrosion, 2012, Article ID: 380217.

[2] Bellakhal, N. and Dachraoui, M. (2004) Study of the Benzotriazole Efficiency as a Corrosion Inhibitor for Copper in Humid Air Plasma. Materials Chemistry and Physics, 85, 366-369.

[3] Bayoumi, F.M., Abdullah, A.M. and Attia, B. (2008) Kinetics of Corrosion Inhibition of Benzotriazole to Copper in 3.5\% $\mathrm{NaCl}$. Materials and Corrosion, 59, 691-696.

[4] Khaled, K.F. (2009) Experimental and Atomistic Simulation Studies of Corrosion Inhibition of Copper by a New Benzotriazole Derivative in Acid Medium. Electrochimica Acta, 54, 4345-4352.

[5] Allam, N.K., Nazeer, A.A. and Ashour, E.A. (2009) A Review of the Effects of Benzotriazole on the Corrosion of Copper and Copper Alloys in Clean and Polluted Environments. Journal of Applied Electrochemistry, 39, 961-969.

[6] Milić, S.M. and Antonijević. M.M. (2009) Some Aspects of Copper Corrosion in Presence of Benzotriazole and Chloride Ions. Corrosion Science, 51, 28-34.

[7] Souissi, N. and Triki, E. (2008) Modelling of Phosphate Inhibition of Copper Corrosion in Aqueous Chloride and Sulphate Media. Corrosion Science, 50, 231-241. 
[8] Khaled, K.F. (2008) Guanidine Derivative as a New Corrosion Inhibitor for Copper in 3\% NaCl Solution. Materials Chemistry and Physics, 112, 104-111.

[9] Tavakoli, H., Shahrabi, T. and Hosseini, M.G. (2008) Synergistic Effect on Corrosion Inhibition of Copper by Sodium Dodecylbenzenesulphonate (SDBS) and 2-Mercaptobenzoxazole. Materials Chemistry and Physics, 109, 281-286.

[10] Behpour, M., Ghoreishi, S.M., Salavati-Niasari, M. and Ebrahimi, B. (2008) Evaluating Two New Synthesized S-N Schiff bases on the Corrosion of Copper in 15\% Hydrochloric Acid. Materials Chemistry and Physics, 107, $153-157$.

[11] Bellakhal, N. and Dachraoui, M. (2003) Electrochemical Investigation of the Oxides Formed at the Surface of Brass (Cu-10Zn) by a Humid-Air Plasma Treatment. Materials Chemistry and Physics, 82, 484-488. http://dx.doi.org/10.1016/S0254-0584(03)00275-X

[12] Dermaj, A., Hajjaji, N., Joiret, S., Rahmouni, K., Srhiri, A., Takenouti, H. and Vivier, V. (2007) Electrochemical and Spectroscopic Evidences of Corrosion Inhibition of Bronze by a Triazole Derivative. Electrochimica Acta, 52, 46544662. http://dx.doi.org/10.1016/j.electacta.2007.01.068

[13] Varvara, S., Muresan, L.M., Rahmouni, K. and Takenouti, H. (2008) Evaluation of Some Non-Toxic Thiadiazole Derivatives as Bronze Corrosion Inhibitors in Aqueous Solution. Corrosion Science, 50, 2596-2604. http://dx.doi.org/10.1016/j.corsci.2008.06.046

[14] Rahmouni, K. and Takenouti, H. (2009) Struggle against Corrosion: Protection by Triazoles Compounds of Ancient and Modern Bronzes Covered with Patina. Actualite Chimique, 327-328, 38-44.

[15] Hu, G., Lu, G.-C., Xu, C.-C. and Wu, X.-H. (2008) Synergistic Effect of Corrosion Inhibition on Bronze by Benzotriazole and Sodium Molybdate. Corrosion Science and Protection Technology, 20, 25-28.

[16] Stupnisek-Lisac, E., Otmacic, H., Tadić, K., Manee, A.D. and Takenouti, H. (2007) Corrosion Protection of Bronze Patina by New Non-Toxic Organic Inhibitors. ECS Transactions, 2, 31-42.

[17] Muresan, L., Varvara, S., Stupnisek-Lisac, E., Otmacic, H., Marusic, K., Horvat-Kurbegovic, S., Robbiola, L., Rahmouni, K. and Takenouti, H. (2007) Protection of Bronze Covered with Patina by Innoxious Organic Substances. Electrochimica Acta, 52, 7770-7779. http://dx.doi.org/10.1016/j.electacta.2007.02.024

[18] Varvara, S., Popa, M., Rustoiu, G., Bostan, R. and Mureşan, L. (2009) Evaluation of Some Amino Acids as Bronze Corrosion Inhibitors in Aqueous Solution. Studia Universitatis Babes-Bolyai Chemia, 2, 73-85.

[19] Hammouch, H., Dermaj, A., Goursa, M., Hajjaji, N. and Srrhiri, A. (2008) New Corrosion Inhibitor Containing Opuntia ficus indica Seed Extract for Bronze and Iron-Based Artefacts. APГYPOMOYAOY TELOS, 149-155.

[20] Emmanuel, S., Souissi, N., Bousselmi, L., Triki, E. and Robiola, L. (2006) Study of the Corrosion Behaviour of Cu10Sn Bronze in Aerated $\mathrm{Na}_{2} \mathrm{SO}_{4}$ Aqueous Solution. Corrosion Science, 48, 2241-2257. http://dx.doi.org/10.1016/j.corsci.2005.08.020

[21] Fiala, A., Chibani, A., Darchen, A., Boulkamh, A. and Djebbar, K. (2007) Investigations of the Inhibition of Copper Corrosion in Nitric Acid Solutions by Ketene Dithioacetal Derivatives. Applied Surface Science, 253, 9347-9356. http://dx.doi.org/10.1016/j.apsusc.2007.05.066

[22] Martinez, S. and Stem, I. (2001) Inhibitory Mechanism of Low-Carbon Steel Corrosion by Mimosa Tannin in Sulphuric Acid Solutions. Journal of Applied Electrochemistry, 31, 973-978.

[23] Abd El Rehim, S.S., Ibrahim, M.A.M. and Khalid, K.F. (2001) The Inhibition of 4-(2'-Amino-5'-methylphenylazo) Antipyrine on Corrosion of Mild Steel in HCl Solution. Materials Chemistry and Physics, 70, 268-273. http://dx.doi.org/10.1016/S0254-0584(00)00462-4

[24] Oguzie, E.E., Onuoha, G.N. and Onuchukwu, A.I. (2005) Inhibitory Mechanism of Mild Steel Corrosion in 2M Sulphuric Acid Solution by Methylene Blue Dye. Materials Chemistry and Physics, 89, 305-311. http://dx.doi.org/10.1016/j.matchemphys.2004.09.004

[25] Marsh, J. (1988) Advanced Organic Chemistry. 3rd Edition, Wiley, Eastern New Delhi. 